\title{
Abreviaturas de patentes na terminologia militar oitocentista da Polícia da Bahia
}

\section{Patent abbreviations in the 19 th Century military terminology of the Police of Babia}

\author{
Luiz Djavan Silva Santos* \\ Secretaria de Educaşão do município de Conceição de Almeida \\ Conceição de Almeida, Bahia, Brasil
}

Sandro Marcío Drumond Alves Marengo**

Universidade Federal de Sergipe

Universidade Estadual de Feira de Santana

São Cristóvão, Sergipe, Brasil

\begin{abstract}
Resumo: Os documentos configuram-se como fontes históricas, na medida em que nos transmitem informações pretéritas, possibilitando-nos acesso à informação de ordens diversas, na dada diacronia estudada, o período da libertação dos escravos e os primeiros dias da República. Este é o caso do Livro do Registro do Detalhe (DET) da Polícia Militar da Bahia, constando as ordens do dia e a rotina do quartel da Mouraria à sua época de escrita. Objetivamos apresentar um fragmento de edição fac-símile e diplomática do DET 68 e, em seguida, descrever as abreviaturas de patentes que aparecem no documento em tela. Ao final, foram totalizadas 64 abreviaturas, dispostas em tabela geral com as suas variantes e o número de ocorrências, comparando as frequências segundo as classificações. Nossa base para estudos das abreviaturas foi centrada nos postulados de Spina (1994), Flexor (2008) e Berwanger e Leal (2008). Este estudo tem sua relevância primária por poder salvaguardar para a posteridade as ordens do dia, exibindo um contexto de usos linguísticos do século XIX. Em segundo lugar, aponta para um campo ainda pouco sistematizado que é o estudo das abreviaturas militares e sua significação social nos processos de produção da escrita oitocentista.
\end{abstract}

Palavras-Chave: Polícia Militar da Bahia. Edição Diplomática. Abreviaturas. Século XIX.

\begin{abstract}
The documents are configured as historical sources, insofar as they transmit past information to us, allowing us access to information of different orders, in the given diachrony studied, the period of the liberation of slaves and the first days of the Republic. This is the case of the Book of the Record of Detail (BRD) of the Military Police of Bahia, with the agenda and routine of the Mouraria barracks at the time of writing. We aim to present a fragment of facsimile and diplomatic edition of BRD 68 and then describe the patent abbreviations that appear in the document on screen. At the end, 64 abbreviations were totaled, arranged in a general table with their variants and the number of occurrences, comparing the frequencies according to the classifications. Our basis for abbreviation studies was centered on the postulates of Spina (1994), Flexor (2008) and Berwanger and Leal (2008). This study has its primary relevance because it can safeguard the agenda for posterity, showing a context of linguistic uses of the 19th century. Second, it points to a field that is still little systematized, which is the study of military abbreviations and their social significance in the production processes of 19 th century writing.
\end{abstract}

Keywords: Military Police of Bahia. Diplomatic Edition. Abbreviations. XIX Century.

\footnotetext{
* Mestre em Estudos Linguísticos pela Universidade Estadual de Feira de Santana (PPGEL/UEFS). Professor da rede municipal do município de Conceição de Almeida-BA. E-mail: djaassis83@hotmail.com. ** Doutorado em Estudos Linguísticos pela Universidade Federal de Minas Gerais (UFMG). Professor da Universidade Federal de Sergipe (UFS) e do Programa de Pós-Graduação em Estudos Linguísticos da Universidade Estadual de Feira de Santana (PPGEL/UEFS), Feira de Santana-Bahia. E-mail: drumondalves@gmail.com.
} 


\section{CONSIDERAÇÕES INICIAIS}

Para Acioli (2003, p.1), “[...] o documento manuscrito é considerado mola-mestra da História [...], representando o melhor testemunho do passado, fonte direta de informação [...]." Dessa forma, ao editar um texto, o pesquisador está enveredando em uma diacronia na tentativa de encontrar respostas para os pressupostos sobre os quais se debruçou para formular o estudo. Assim, este artigo apresenta uma edição fac-símile e diplomática de alguns fólios das ordens do dia de um documento oitocentista referente a um Livro de Registro do Detalhe da Polícia Militar da Bahia e um estudo descritivo sobre as abreviaturas de patentes militares contidas no documento editado.

Com o objetivo de construir um percurso que possibilite ao nosso leitor um melhor entendimento do trabalho empreendido, apresentamos inicialmente, de modo linear e panorâmico, a história da Polícia Militar da Bahia circunscrita temporalmente somente ao século XIX. Nossa proposta foi trazer um apanhado histórico que vai da criação do Corpo de Polícia e sua estruturação enquanto corporação desde as origens até o marco da Proclamação da República, em 1889. A importância dessa seção reside no fato de contextualizar o nosso leitor sobre a época estudada, bem como sobre a Instituição onde (e para quem) o corpus editado foi produzido. Na sequência, relatamos o que é um Livro de Registro do Detalhe bem como apresentamos suas características materiais.

Em seguida, nos debruçamos sobre considerações e conceituações sobre as abreviaturas, suas tipologias e sua forma de classificação. Nos procedimentos metodológicos damos a conhecer a delimitação do corpus, o norteamento para a produção das edições fac-símile e diplomática, o tratamento dispensado para a coleta, organização e classificação das abreviaturas das patentes militares. Por fim, apresentamos os extratos das edições previstas, descrevemos e classificamos as abreviaturas contidas na fonte documental trabalhada. É importante mencionar que esse artigo é fruto de resultados mais amplos obtidos na pesquisa de mestrado acadêmico em estudos linguísticos de um de seus autores e, também, de uma pesquisa empreendida com financiamento do CNPq (Processo 406884/2017-0) na categoria de Pós-Doutorado Júnior (PDJ) do segundo autor.

\section{UMA BREVE ACHEGA SOBRE A POLÍCIA BAIANA OITOCENTISTA}

Como nosso estudo está assentado em um documento produzido no seio da PMBA, no interstício temporal compreendido entre a assinatura da Lei Áurea e a proclamação da República, faremos uma breve contextualização da situação do Brasil neste período. Convém esclarecer que fazer, ainda que breve, uma achega histórico-militar do período onde nosso corpus está localizado é importante, pois é bastante difícil pensar “[...] a história militar como algo inerentemente distinto da história mais ampla da sociedade de onde soldados e oficiais são recrutados" (CASTRO et al., 2004, p. 12).

A criação definitiva de um Corpo de Polícia da Bahia foi determinada pelo decreto imperial de 17 de fevereiro de 1825, tendo como objetivo trazer a tranquilidade e a segurança pública para a Bahia. Esse decreto estipulava a forma como a corporação seria organizada, bem como sua composição: basicamente um estado maior, em que o comandante deveria portar a patente mínima de Major, e duas companhias de infantaria. 
14 anos depois, foi promulgada a Lei $n^{\circ} 95 \mathrm{da}$ Bahia, em que se outorgava autoridade ao governo para que, toda vez que se fizesse necessária a garantia da Lei e da Ordem, o efetivo de praças e oficiais pudesse ser aumentado, para que estes empregassem a força armada para controlar situações de conflito.

Com o desenvolvimento do Corpo de Polícia e a criação de uma Secretaria de Segurança Pública em 1841, fez-se necessário o estabelecimento de um regulamento para a Corporação que despontava como uma vigorosa instituição de manutenção da segurança na província da Bahia. Diante disso, o governador da província, o TenenteGeneral Francisco José de Souza Soares Andréa, Barão de Caçapava, espelhando-se no Regulamento do Corpo de Permanentes da Corte, criou o regulamento da corporação da província da Bahia, em março de 1845, sob a lei $n^{\circ} 2221$, fazendo as devidas adaptações à realidade baiana. Araújo (1997) aponta que o supracitado Barão também foi o responsável por estipular um contingenciamento mínimo de praças e oficiais que deveriam compor os destacamentos do Corpo de polícia, fossem eles assentados na capital ou no interior.

É importante destacar que a situação política do Brasil no século XIX era demasiado conturbada ${ }^{1}$ e, para tanto, mais homens seriam necessários para garantir a segurança pública das províncias. Por isso, os homens que compunham a Guarda Nacional foram requisitados para auxiliar a aplacar as ideias republicanas e federalistas que se propagavam na capital, onde os revoltosos investiam, com maior ênfase, por ser o centro político da província. Contudo, o aumento do efetivo e o cumprimento de suas demandas resultaram em gastos tanto para o governo central quanto para a província. Como a situação financeira do momento não era das melhores, mesmo diante do quadro de revoltas e levantes, a província da Bahia teve que enxugar a folha de pagamento e a primeira redução foi gerada com o pessoal responsável pela garantia do policiamento, que, no ano de 1845 , teve seu efetivo reduzido de quase 600 homens para somente 452.

Entretanto, com a intensificação dos conflitos nos quais os rebeldes queriam tomar a província e declarar a dependência da mesma, se fez necessário, por questões estratégicas, novamente a ampliação do efetivo para o ano de 1847, chegando naquele momento a 600 homens distribuídos, conforme nos diz Araújo (1997, p. 11), em “[...] Estado Maior, Estado Menor, quatro Companhias de infantaria e uma de cavalaria".

Ainda segundo o autor, esse período foi muito delicado para o policiamento na Bahia, porque o Império brasileiro, que estava envolvido com a guerra na província Cisplatina, convocou todas as guarnições do Exército para retornar à Corte e auxiliá-la nesse conflito. Diante desse quadro, o Presidente da província criou mais duas companhias de Polícia, tendo cada uma 100 praças, que seriam pagos pelos cofres gerais. Essa ação foi gerada no intuito de melhorar a segurança pública e, por conseguinte, fortalecer o Corpo de Polícia para futuras empreitadas dos revoltosos. Assim, segundo Araújo (1997), já em 1854, ano no qual foi instaurado o regulamento para a Corporação de Polícia, a referida organização já dispunha de 857 homens.

\footnotetext{
1 A partir das leituras de Dolhnikoff (2017), o litígio entre Conservadores e Liberais pelo poder e o Imperador D. Pedro II lutando para manter-se no centro da política a qualquer custo são alguns episódios que marcaram essa conturbação política.
} 
Dois anos depois, ainda na tentativa de se ampliar a segurança da capital, o governo da província criou uma guarda urbana para auxiliar no policiamento ostensivo da cidade. Para facilitar a inspeção das devidas companhias, bem como aplicar a sistematização que se instalara na corporação, o Major do Exército Domingos José Freire de Carvalho sugeriu que o Corpo de Polícia fosse dividido em distritos, tendo a figuração tal qual podemos observar no quadro a seguir:

Quadro 1: Estruturação do Corpo em Distritos

\begin{tabular}{|c|c|l|}
\hline Distrito & $\begin{array}{l}\text { Companhia } \\
\text { responsável }\end{array}$ & \multicolumn{1}{|c|}{ Cidades, freguesias e vilas } \\
\hline $1^{\text {o }}$ & $1^{\mathrm{a}}$ & $\begin{array}{l}\text { Vila de Abrantes, Mata de São João, Cachoeira, Maragogipe, } \\
\text { Santo Amaro, Vila de Feira de Santana, Vila do Conde, Vila da } \\
\text { Tapera, Freguezia de Lage, Vila de Camisão, Vila de São } \\
\text { Francisco, Nazaré, Itaparica e Jaguaripe }\end{array}$ \\
\hline $2^{\text {o }}$ & $4^{\text {a }}$ & $\begin{array}{l}\text { Ilhéus, Porto Seguro, Caravelas, Vila de Alcobaça e Prado, Vila } \\
\text { de São José do Pôrto Alegre }\end{array}$ \\
\hline $3^{\text {o }}$ & $3^{\text {a }}$ & $\begin{array}{l}\text { Vila de Caiteté, Vitória, Urubu, Monte Alto, Vila de } \\
\text { Carinhanha, Macaúbas }\end{array}$ \\
\hline $4^{\circ}$ & $2^{\text {a }}$ & $\begin{array}{l}\text { Jacobina, Vila Nova da Rainha, Sento Sé, Juazeiro, Pilão } \\
\text { Arcado }\end{array}$ \\
\hline $5^{\text {o }}$ & $5^{\text {a }}$ & $\begin{array}{l}\text { Inhambupe, Vilas da Purificação e Alagoinhas, Itapirucu, } \\
\text { Pombal, Tucano, Capim Grosso }\end{array}$ \\
\hline
\end{tabular}

Fonte: Autoria própria a partir de Araújo (1997)

Araújo (1997) afirma que a divisão da Corporação nesses distritos facilitou a distribuição do policiamento na província, pois os comandantes de cada Companhia eram responsáveis diretamente por sua supervisão e fiscalização. Essa divisão, portanto, possibilitou um maior controle e norteio dos procedimentos e estratégias militares a serem traçadas nas regiões cobertas pelos distritos, bem como a ordem e orientações aos praças e soldados passaram a ser mais minuciosas e seus resultados mais eficazes, uma vez que os eventuais desertores ou aqueles que não se enquadrassem nas diretrizes de conduta eram rapidamente punidos. Isso, de certa forma, evitou um caos corporativo com debandadas e insubordinações contundentes por meio de motins, muito comuns à época.

Mesmo com uma melhor distribuição, o número do efetivo policial ainda estava aquém das demandas geradas. Diferentemente do Exército, o Corpo de Polícia não podia fazer recrutamento ou contar com o voluntariado. Além disso, o forte rigor com a disciplina e conduta dos praças e oficiais, dentro e fora dos quartéis, passou a afugentar potenciais ingressantes. No entanto, é importante ressaltar que tal atitude era necessária para aplacar qualquer tentativa de motim contra os superiores ou mesmo de burlar as ordens da corporação ${ }^{2}$. Por isso, os comandantes eram rigorosos, podendo aplicar pena de rebaixamento por até 15 dias, se a infração fosse algo grave. Os insubordinados seriam

\footnotetext{
${ }^{2}$ Frisamos que, segundo Araújo (1997), em caso de rebelião ou invasão externa, o Corpo de Polícia ficaria seria regido automaticamente pelo regulamento do Exército brasileiro.
} 
submetidos a um conselho de investigação ${ }^{3}$. Os praças que fossem pegos em atos indisciplinares eram conduzidos ao Exército como recrutas.

Como uma forma de amenizar a reverberação negativa dos tratamentos dispensados aos homens do Corpo de Polícia, o governo passou a fazer elogios constantes à corporação. Conseguir aumentar o efeito do Corpo de Polícia passou a ser uma necessidade do Império, pois, em 1864, o Brasil se envolveu em litígio contra o Paraguai e, por isso, todo o efetivo do Corpo de Polícia permanente foi convocado à guerra. Contudo, não se poderia deixar a província desguarnecida. Para tanto, segundo Araújo (1997), por meio da Lei no 961, de 4 de maio de 1865, houve a criação de um corpo provisório de polícia, tendo o mesmo quantitativo do efetivo que fora convocado para a guerra. No entanto, ao findar o conflito internacional, os homens que compuseram o corpo provisório foram automaticamente inseridos como permanentes ${ }^{4}$ na Corporação. Embora grandes esforços tenham sido feitos no sentido de atrair novos praças ao Corpo de Polícia, o resultado não foi satisfatório.

Ao longo de todo o século XIX, sucessivas legislações foram criadas ora para aumentar o efetivo do Corpo policial, ora para reduzi-lo com a justificativa de contenção de despesas governamentais. Somente após a proclamação da República no Brasil, o Corpo de Polícia, pelo decreto de 5 de dezembro de 1889, reformulou a corporação dando-lhe o nome de Corpo Militar de Polícia, que corresponde à Polícia Militar da Bahia que conhecemos nos dias atuais. Com essa achega apresentamos a macro história em que o nosso objeto de estudo foi confeccionado. A seguir, apresentaremos de modo mais pormenorizado o que são os livros de registro do detalhe e as especificidades do número 68, em particular.

\section{OS LIVROS DE REGISTRO DO DETALHE}

Com a estruturação do Corpo de Polícia na Bahia era importante, administrativamente, o acolhimento de um instrumento que pudesse registrar as informações dadas e recebidas no seio da corporação, bem como sistematizar uma sequência de rotina no dia-a-dia no Quartel. Além disso, esse instrumento também daria celeridade tanto nas comunicações internas do quartel quanto nas externas a elas como, por exemplo, as estabelecidas entre o governo da província, o governo Imperial e a Corporação de Polícia.

Desse modo, a corporação adotou um sistema de escrituração que teve como modelo o que os Exércitos, principalmente o português e o brasileiro, baseados em decretos pombalinos, dispunham (MARENGO, 2016), colocando nas secretarias das corporações policiais dois livros: um para os oficiais- as chamadas fés de ofício- e praçasos assentamentos; e outro que continha as ordens do dia e os detalhes das atividades da corporação, que eram intitulados de Livros de Registro do Detalhe, terminologicamente conhecidos como DET dentro da estrutura da Polícia Militar. As ordens do dia, conforme

\footnotetext{
${ }^{3} \mathrm{Na}$ atualidade, seria o correspondente ao Inquérito Policial Militar (IPM).

${ }^{4}$ A Lei no 1131 , de 6 de janeiro de 1870, em seu artigo $6^{\circ}$, determinou que o Corpo Provisório se tornasse efetivo, assim que o Corpo Permanente retornasse da guerra do Paraguai.
} 
já dissemos anteriormente, traziam os relatos mais importantes da rotina militar ou de fatos externos que se julgasse importante no cotidiano da corporação. Por isso, há relatos que tratam de temas diversos: prisões de soldados que cometiam insubordinação, mudança de patente, transferência de companhia, nota de falecimento, troca de comando, desligamento de pessoal que tinha o "vício da embriaguez", comunicação entre o presidente da província e a corporação, entre outros. O nosso objeto de estudo pertence a esse último grupo.

O DET 68, que corresponde ao registro das ordens do dia do período de 13 de março de 1885 a fevereiro de 1890, está encadernado em forma de livro, com sua capa cartonada medindo 436 × $305 \mathrm{~mm}$. Sua lombada tem 436 × $47 \mathrm{~mm}$. Seus 200 fólios de média gramatura são pautados com 46 linhas e tem dimensão total de 430 x $295 \mathrm{~mm}$. O livro é totalmente manuscrito, na maioria dos fólios em recto e verso, com tinta ferrogálica. Encontramos nomes próprios sublinhados a lápis azul e vermelho, que indicam condições de incorporação e baixa, respectivamente, da tropa. A mancha de escrita mede 366 × $250 \mathrm{~mm}$. Os fólios são numerados somente no recto por números impressos, seguidos de rubricas de assinatura, na parte superior direita. O documento está em bom estado de conservação. Santos (2019) nos conta ainda que, no ano de 2017, a coleção dos DET recebeu a chancela do Programa Memória do Mundo da Organização das Nações Unidas para a Educação, a Ciência e a Cultura (UNESCO).

\section{SOBRE AS ABREVIATURAS}

O uso de abreviaturas nos procedimentos de escrita não é algo recente. Não foi uma alcunha dos ambientes digitais da era da internet e muito menos pode ser considerada uma primazia da contemporaneidade. Os documentos antigos também faziam uso do recurso de abreviaturas. Algumas delas conhecidas até hoje, outras nem tanto. Dessa forma, é fato que "[...] existem abreviaturas de documentos, dos séculos XVI ao XIX, bastante conhecidas e ainda usadas, mas, a par dessas, encontram-se outras desconhecidas na atualidade ou que caíram em desuso. Tanto umas quanto outras são indicadas com suas respectivas datas" (FLEXOR, 2008, p. 11).

Spina (1994), Dias e Bivar (2005) e Flexor (2008) assinalam que o sistema abreviativo se originou na Roma Antiga, através de um tipo de escrita muito praticada, a taquigrafia. Sua etimologia vem do grego clássico: tachus (rápido) e graphein (escrever). Assim, sua configuração é de um tipo de escrita tão rápida quanto a fala, já que o costume era transcrever os discursos proferidos ao vivo. Em relação à taquigrafia, naquele período, era muito comum a presença de notas tironianas (notae tironianae). Então,

[...] de acordo com os paleógrafos latinos, são a mais antiga forma de "taquigrafia" européia. Por longo tempo foram quase indecifráveis e, em virtude disso, incluídas entre as escritas misteriosas dos tempos antigos. Desde o século XVI, estudiosos publicaram obras acerca desse tipo de anotação. [...] Chamam-se notas tironianas porque se atribui tal invenção ao liberto de Cícero, Tullius Tiro. [...] a maioria dos autores aceita como inventor Tiro, que se servia desse sistema "taquigráfico" para captar, na íntegra, em tábuas enceradas e estilete, os discursos dos mais famosos oradores romanos. (FLEXOR, 2008, p.11) 
Nesse bojo, tal qual postula Millares Carlo (1929, p. 46), tendo as notas tironianas como um modelo a ser seguido, os magistrados começaram a utilizar em seus códices um sistema abreviativo complexo e completo e, assim, surgem as notas jurídicas. Sobre elas, Lima (2006, p. 11) nos faz perceber que não tiveram a mesma aceitação popular, tal qual as notas tironianas, mas algumas persistem, como v.g. (verbi gratia, por exemplo) e s.m.j. (salvo melhor juízo). Outro aspecto relevante a ser considerado sobre as abreviaturas é o fato de que seu uso, nos primórdios de sua aplicação, apresentava um caráter de formalidade. Então, por seu caráter formal, as abreviaturas tinham seu uso como praxe em documentos oficiais. Flexor (2008) afirma que:

As abreviaturas eram tão comuns nos documentos, até o século XIX, que se pode citar o curioso exemplo de sua presença nos "pasquins", ou panfletos, afixados pela cidade do Salvador, em agosto de 1798, e que dariam origem ao processo da chamada Conspiração dos Alfaiates. Isso significa que a própria população estava familiarizada com essa forma de grafar as palavras. No conjunto desses documentos da conspiração existentes no Arquivo do Estado da Bahia encontram-se, também, alguns exemplos de abreviaturas ou sinais não convencionais, como datas, algarismos romanos, números ordinais etc. (FLEXOR, 2008, p. 12)

A assertiva trazida pela pesquisadora supracitada nos leva a compreender que não havia uma uniformização ou padronização no uso das abreviaturas. Não se tinha uma regra definida, principalmente se cotejamos as convenções de uso das abreviaturas na Europa e as luso-brasileiras. Assim,

Para os documentos luso-brasileiros não existem regras de abreviações, mais usuais nos documentos europeus de outras regiões. Entretanto, algumas delas foram normal e comumente utilizadas pelos calígrafos ou escrivães, como, por exemplo: $\mathrm{m}^{\mathrm{e}} \mathrm{ou} \mathrm{m}^{\mathrm{te}}$ indicando a abreviação do sufixo mente, como na palavra juntam ${ }^{\mathrm{e}}$ ou juntam $^{\text {te }}=$ juntamente. Outros exemplos de abreviaturas com sufixos imutáveis podem ser encontrados no final deste trabalho. (FLEXOR, 2008, p.12)

No entanto, é bom entendermos que a linguagem se relaciona ao uso. Diante disso, à época, havia uma necessidade de conter os custos com a escrita, pois fazer um documento era muito caro. Segundo o que nos afirmam Carneiro e Souza (2015) ao dizer que:

Era um trabalho cansativo, mas o principal objetivo era de ordem econômica uma vez que a tinta e o papel eram caríssimos. O preço de um Código Penal, por exemplo, segundo Silva Neto, chegava a custar 17 bois, ou 50 porcos, ou 200 carneiros, por volta do século XVIII. (CARNEIRO; SOUZA, 2015, p. 62)

Outro fato a ser destacado é o de que os copistas tinham que transcrever os relatos de forma rápida, para tanto, o uso de abreviaturas se configurava como uma economia de tempo. Sobre isto, Flexor (2008) nos leva a refletir acerca desse uso recorrente na Idade Média, apontando que

Os calígrafos de todos os tempos, mas de modo especial os da Idade Média, quer para poupar espaço, devido à escassez de materiais de base e de registro, quer por economia de tempo, 
fizeram uso de um completo sistema de abreviaturas, siglas e das chamadas notas tironianas, prática que permaneceu após aquele período. (FLEXOR, 2008, p. 12)

O uso de abreviaturas foi crescente e recorrente na Idade Média. Esse crescimento, fez com que as abreviaturas se tornassem mais diversificadas e, por conseguinte, mais complicadas nesse período histórico (FLEXOR, 2008). Já Berwanger e Leal (2008, p. 91 92), conformes às proposições da autora citada anteriormente, apontam que as abreviaturas nos documentos tornaram-se um modismo, dificultando a compreensão do texto.

Dessa forma, fez-se necessário conter o crescente uso das abreviaturas. Com isso, Spina (1994, p. 49-50) esclarece que no declínio da República romana, o uso em excesso de abreviaturas fez com que algumas medidas fossem estipuladas para delimitar seu uso, mas tal ordenamento não produziu efeito prático em seu uso. Ampliando a visão de Spina (1994), Berwanger e Leal (2008, p. 92) elucidam que “[...] o código de Justiniano proibiu a sua utilização em documentos jurídicos. Após o século IX d.C. há um modismo em abreviar palavras, mas nos séculos XII e XIII tomaram-se providências no sentido de proibir as abreviaturas." Ainda assim, durante o Renascimento, "[...] o hábito das abreviaturas continuou, a ponto de, para as obras jurídicas, serem até publicadas tábuas especiais para a leitura das siglas" (SPINA, 1994, p. 50). Mesmo com o passar dos anos, o uso de abreviaturas continuou sendo uma prática comum na escrita. Dessa feita, nos deteremos em sua classificação. Para tanto, devemos registrar que as entendemos como integrantes genuínas do léxico de uma língua natural, estando sujeitas aos processos de formação que delineiam essa taxonomia.

No que tange a composição das abreviaturas, Cintra e Cunha (2007) nos levam a entender que a globalização acelerou o cotidiano das pessoas, levando-as a ter celeridade nas elocuções e interações que fazem. Para eles, "[...] economizar tempo e palavras é uma tendência geral do mundo de hoje” (CINTRA; CUNHA, 2007, p.130). Assim, as classificações das abreviaturas que seguiremos são as formadas por processos de apócope e síncope, seguindo a visão de Spina (1994) e Flexor (2008). Balizadas pelos processos de supressão, as abreviaturas podem ser: a) Abreviaturas apocopadas (processo de apócope): quando a abreviatura obtida suprime o final da palavra. Por exemplo, nas ordens do dia editadas, é comum o termo com. = companhia. $\mathrm{Na}$ composição da abreviatura a parte final da palavra foi retirada, permanecendo assim, a parte inicial; b) Abreviaturas por síncope: Nesse processo, a palavra que foi reduzida, perde letras no meio da mesma, ficando o início e o final da palavra. Como exemplo, podemos citar, Commande. $=$ commandante, lembrando que à época era comum a presença das geminadas $\mathrm{mm} / \mathrm{nn} / \mathrm{p}$. Observamos que na formação da abreviatura a parte inicial e final da palavra foram mantidas, eliminando as letras que estavam presentes no meio da mesma.

Além da classificação tomada pelo tipo de formação, podemos pensar na classificação das abreviaturas segundo a sua forma estrutural no suporte de escrita. Assim, por exemplo, Flexor (2008, p. 14) nos traz a nomeação de abreviaturas com letras sobrescritas $^{5}$ - em que, em geral, é colocada a letra inicial ou prefixo da palavra, e, em

${ }^{5}$ Conceito também trazido por Spina (1994, p. 51), Berwanger e Leal (2008). 
suspensão, a última ou as últimas letras da palavra. Por exemplo: $S^{o r}=$ senhor; $S^{\prime \circ}=$ santo; $T^{a m}=$ tabelião; Capp $p^{a m}=$ capitão." Nas ordens do dia do nosso corpus, por exemplo, temos $E X^{\prime m o}=$ excelentíssimo, comp $p^{a} .=$ companhia. Observemos que são abreviaturas formadas pelo processo de síncope, ficando a parte inicial como a base e a parte final como um sobrescrito.

Outra classificação, dessa vez, estabelecida por Spina (1977) é a de numeral inicial com letra(s) sobreposta(s) ou, simplesmente, abreviatura numérica. Por exemplo, $8^{b r o}$ (outubro). Outra discussão levantada por Flexor (2008) refere-se às siglas, apresentada pela autora como "[...] letras maiúsculas do alfabeto que sozinhas representam palavras completas e das quais são a inicial. Por exemplo: $\mathrm{B}=$ beato; $\mathrm{D}=$ dom; $\mathrm{P}=$ padre; PNAM = Padre Nosso, Ave Maria [...]" (FLEXOR, 2008, p.13). Como a constituição de siglas também segue um processo formal de formação, enquadrando-se nos metaplasmos, podemos admiti-las como uma forma de classificação. Outrossim, se configuram como uma forma de apócope, uma vez que preservamos a letra inicial, suprimindo a parte final. Em sua explanação, Flexor (2008) amplia a discussão sobre as siglas, dividindo-as em três tipos, a saber:

1. siglas simples - quando indicadas apenas por uma letra, como os exemplos acima; 2. siglas reduplicadas - quando a letra é repetida para significar o plural das palavras representadas, ou quando, na palavra, a letra é encontrada pelo menos duas vezes. Por exemplo: SS = santíssimo, $\mathrm{RR}=$ reverendíssimo ou reverendíssimos, $\mathrm{PP}=$ padres ou paternidades; 3 . siglas compostas - quando são formadas pelas duas ou três primeiras letras da palavra ou pelas letras dominantes do vocábulo. Por exemplo: MOBRAL $=$ Movimento Brasileiro de Alfabetização, SUDENE = Superintendência de Desenvolvimento do Nordeste, de uso mais recente. (FLEXOR, 2008, p. 14).

Por fim, há mais uma classificação que são as abreviaturas de sinais especiais, apresentadas por Flexor (2008, p. 14) e Berwanger e Leal (2008), sendo que todos os pesquisadores citados as apresentam como a alocação de um sinal qualquer na palavra (início, meio e fim). Por exemplo, cõtě = contém; comû = comum.

Assim, nosso apanhado teórico sobre as abreviaturas, sua tipologia e classificação, atende ao nosso propósito nesse artigo. A partir do que apresentamos aqui, seremos capazes de classificar as abreviaturas que apareceram no corpus que apresentamos previamente.

\section{PROCEDIMENTOS METODOLÓGICOS}

Como temos um espaço exíguo para este artigo, não é possível apresentar a edição fac-símile e diplomática de todos os fólios do DET68 que correspondem ao período histórico localizado entre a libertação dos escravos (13 de maio de 1888) e a Proclamação da República (15 de novembro de 1889). Os fólios correspondentes a esse lapso temporal correspondem ao intervalo de $116 \mathrm{r}$ até $156 \mathrm{v}$. Assim, para esse artigo optamos por apresentar uma amostragem da edição expressa pelo fólio inicial (116r) e o final (156v). 
Nosso intuito é tão somente o de trazer à luz o modo como fizemos as edições para a extração dos nossos dados de abreviaturas.

A edição diplomática foi construída a partir da edição fac-símile. A digitalização do material e seu tratamento para edição fac-similar foram realizados no Laboratório de Humanidades Digitais e Documentação Terminológica (LADOC) da Universidade Federal de Sergipe (UFS). O aparelho usado para digitalização foi um escâner i2S DIGIBOOK (França), modelo E-Scan Agate 10, do tipo planetário. A imagem foi realizada por captura matricial por CCD de área, trabalhada com resolução de 300dpi e armazenada em formato jpeg.

A escolha do tipo de edição de um texto requer um cuidado especial, pois, além das especificidades de normas que devem regê-la, há de se considerar o público-alvo a quem ela vai destinada primordialmente (MARENGO, 2016; CAMBRAIA, 1999). Para essa pesquisa, voltada exclusivamente para mapeamento e descrição das abreviaturas de patentes militares da Polícia da Bahia, a escolha recaiu sobre a edição diplomática que, segundo Cambraia (2005), respeita o máximo possível das características originais das fontes e não há uma intervenção direta do editor a não ser no que diz respeito ao tipo de letra. Assim, esse seria o único tipo de edição interventiva que não ocasionaria qualquer tipo de modificação nas abreviaturas.

As normas que regeram a edição foram tomadas, com suas devidas adaptações, do Projeto Para História do Português Brasileiro (PHPB), uma vez que nosso objeto de estudo também será incorporado ao banco de dados do projeto. As normas usadas seguiram o que nos apresentam Marengo e Freitag (2016) e Marengo (2018), com sua versão para edições diplomáticas:

1. A transcrição foi conservadora, com letra média times new roman 10.

2. As abreviaturas não foram desenvolvidas. Respeitou-se a grafia original do DET.

3. Não foi estabelecida fronteira de palavras que vieram escritas juntas, nem se introduziu hífen ou apóstrofo onde não havia.

4. A pontuação e a acentuação originais foram mantidas.

5. Os sinais de separação de sílaba ou de linha foram mantidos como no original.

6. Foi respeitado o emprego de maiúsculas e minúsculas como no original.

7. As cores azul e vermelha, usadas para sublinhar passagens do texto, foram mantidas.

8. A divisão das linhas do documento original foi preservada ao longo do texto.

9. A mudança de fólio ou página recebeu a marcação [Fól.] entre colchetes com o respectivo número e indicação de frente ou verso. Fora dos colchetes, nos fólios do recto, foi indicada, em negrito, a marcação impressa de página constante no DET.

11. Para esta edição específica, as linhas não foram numeradas.

12. As assinaturas e rubricas simples foram sublinhadas e indicadas entre colchetes.

A edição diplomática foi convertida em arquivo formato txt para ser processada pelo programa AntConc versão 3.5.8 para Windows, que permite buscas e realização do cálculo da ocorrência/frequência das palavras em um determinado corpus escrito. Para permitir uma análise focada apenas nos itens lexicais substantivos, em que se alocam os designativos de patentes militares, confeccionamos uma lista de exclusão contendo todos 


\section{Revista \\ ${ }_{A}$ Cor das Letras}

os itens gramaticais não substantivos para que fossem eliminados no processamento de geração de dados no programa.

Após processado o arquivo, utilizamos o recurso Wordlist para obter a lista de lexias (types) com seu número de ocorrências (tokens) ordenada do maior número para o menor. Em seguida, de modo manual, selecionamos somente as ocorrências em abreviaturas e, por fim, somente as abreviaturas correspondentes aos graus hierárquicos de patente. $\mathrm{Na}$ sequência da delimitação, organizamos e classificamos os dados segundo as acepções teóricas de Spina (1977) e Flexor (2008). A seguir, apresentamos os resultados circunstanciados das edições realizadas.

\section{FRAGMENTOS DA EDIÇÃO FAC-SÍMILE E DIPLOMÁTICA DO DET 68}

Figura 1: Edição Fac-símile do fólio 116r do DET 68

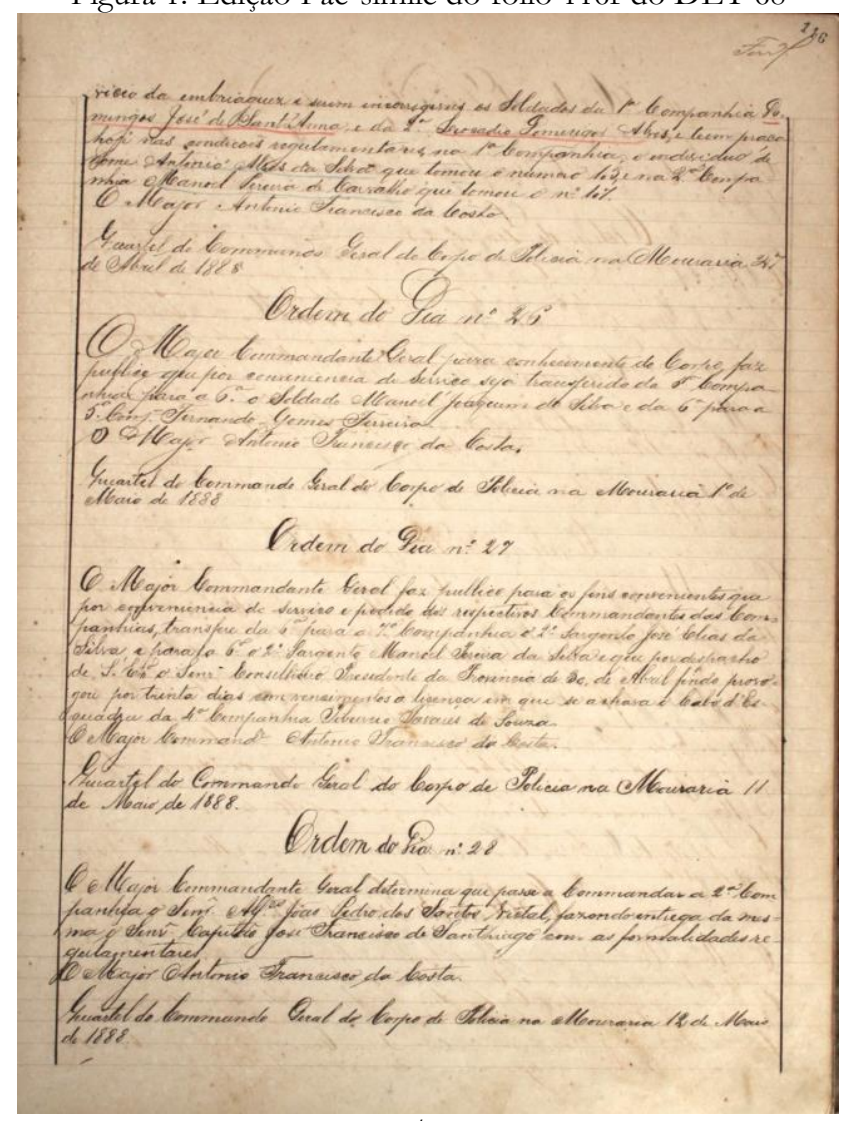

Fonte: realizada pelo LADOC/UFS com autorização da PMBA

\section{[Fól.116r] 116}

Oficio da embriagues e serem incorrigiveis os Soldados da 1. '. Companhia Domingos José de Sant' Anna e da 2. 'Leocadio Domingos Alves, e teem praça hoje nas condiçoes regulamentares, na 1. Companhia; o individuo de 
nome Antonio Alves da Silva que tomou o numero 103, e na 2. Compa nhia Manoel Pereira de Carvalho que tomou o n-. 107.

O Major Antonio Francisco da Costa

Quartel do commando Geral do Corpo de Polícia na Mouraria 27

Abril de 1888

Ordem do Dia n. ${ }^{\circ} 26$

O Major Commandante Geral para conhecimento do corpo faz

Publico que por conveniencia do serviço seja transferido da 5. Companhia para a 6." o Soldado Manoel Joaquim da Silva e da 6. para a

5. Comp. Fernando Gomes Ferreira.

O Major Antonio Francisco da Costa.

Quartel do Commando Geral do Corpo de Policia na Mouraria $1^{\circ}$. De

Maio de 1888.

Ordem do Dia n. ${ }^{\text {o }} 27$

O Major Commandante Geral faz publico para os fins convenientes que por conveniencia do serviço e pedido dos respectivos Commandantes das com= panhias, transfere da 6." para a 7. "Companhia o $2^{\circ}$ Sargento José Elias da Silva e para a 6. o 2 . $^{\circ}$ Sargento Manoel Ferreira da Silva e que por despacho de S. Ex. o Senř. Conselheiro Presidente da Provincia de 30, de Abril findo proro= gou por trinta dias com vencimentos a licença em que se achava o Cabo d' Es= quadra da 4. ${ }^{\mathrm{a}}$ Companhia Tiburcio Tavares de Souza.

O Major Commande. Antonio Francisco da Costa.

Quartel do Commando Geral do Corpo de Policia na Mouraria 11 de Maio de 1888.

Ordem do Dia n. 28

O Major Commandante Geral determina que passe a commandar a 2. ${ }^{\text {a Com- }}$

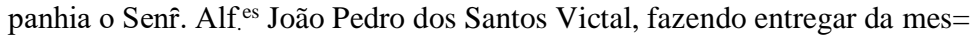
ma o Senr̂. Capitão José Francisco Santhiago com as formalidades re-

gulamentares.

O Major Antonio Francisco da Costa.

Quartel do Commando Geral do Corpo de Policia na Mouraria 12 de Maio de 1888 . 
an.

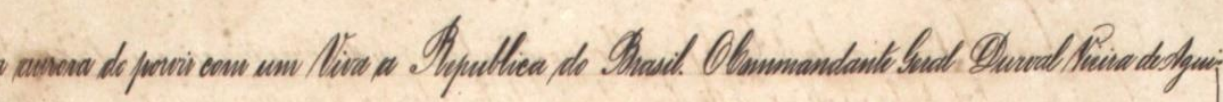
Luara

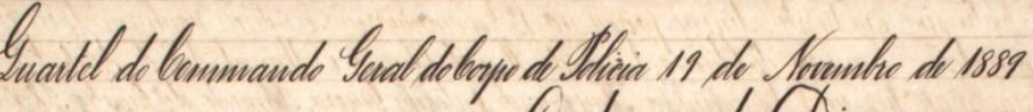
cudim dogian $n \div 2$

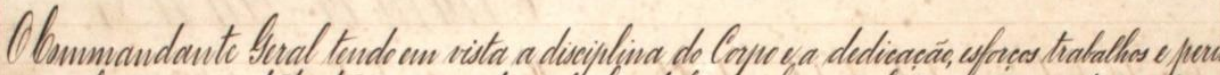

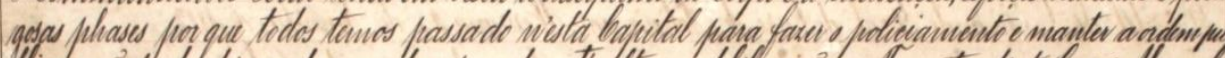

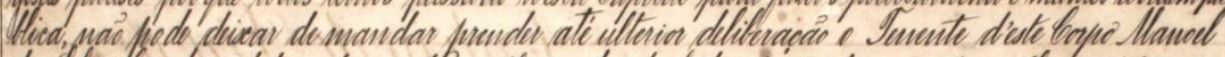

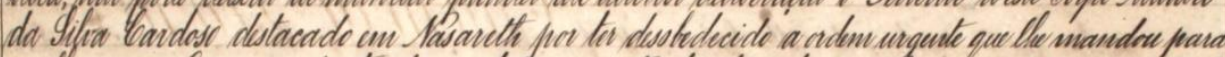

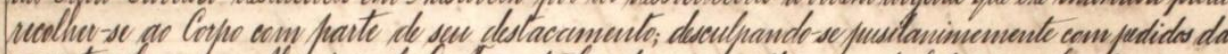

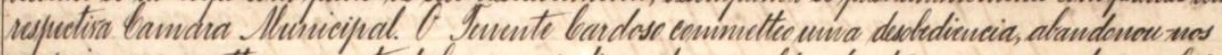

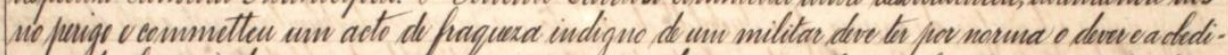

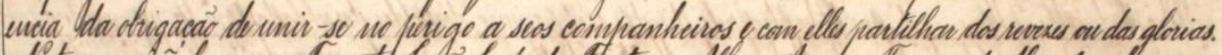

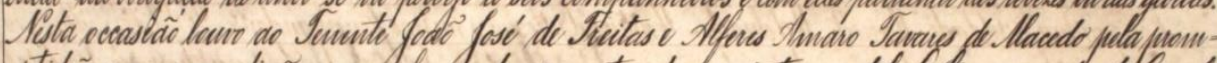

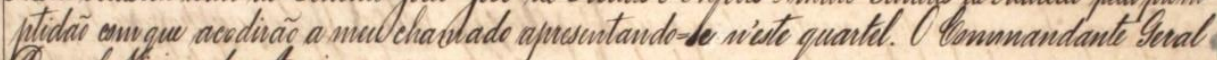
Doural ticina de tguiar

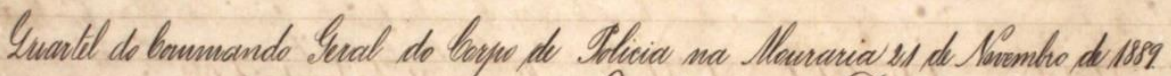
Drdion do Qhid n:-3

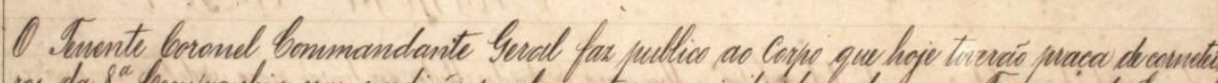

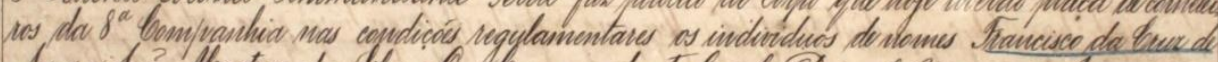

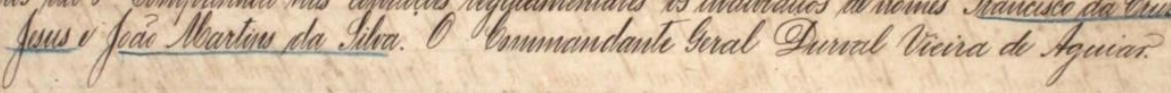

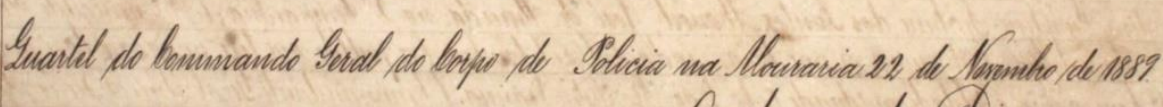
Gudem do gian $\div$ :4.

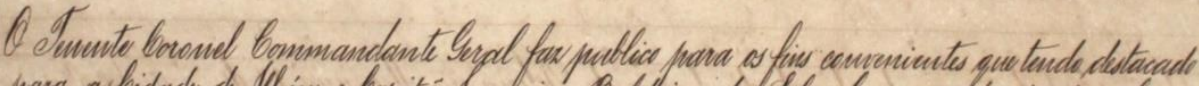

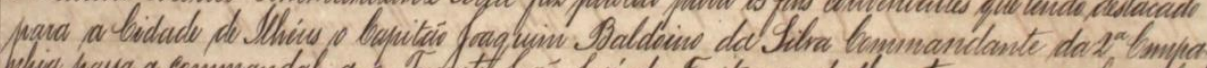

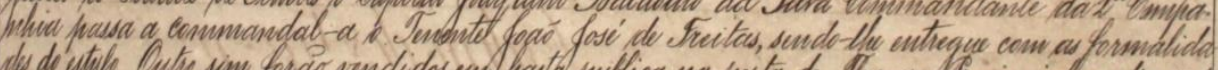

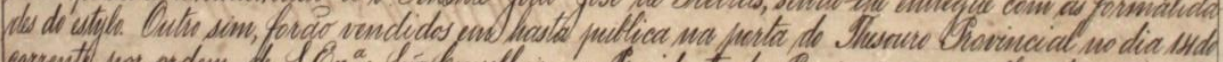

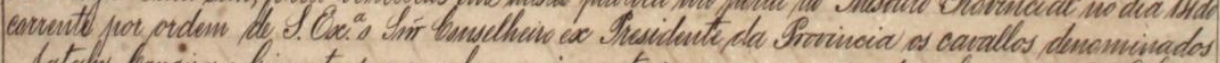

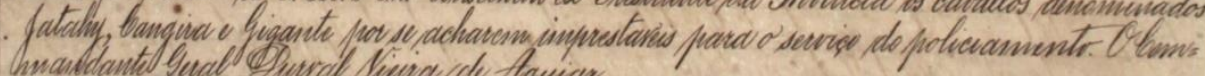

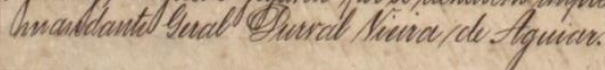

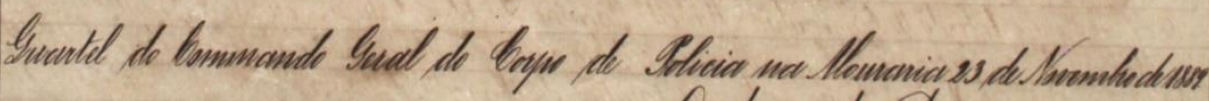
Qudem de Gia $n \div 5$

Fonte: realizada pelo LADOC/UFS com autorização da PMBA 


\section{[Fól.156v]}

a aurora do porvir com um Viva a Republica do Brasil. O Commandante Geral Durval Vieira de Agui= ar.

Quartel do Commando Geral do Corpo de Policia na Mouraria 19 de Novembro de 1889

Ordem do Dia n-2

O Commandante Geral tendo em vista a disciplina do Corpo e a dedicação, esforços trabalhos e peri= gosas phases por que todos temos passado n'esta Capital para fazer o policiamento e manter a ordem pu= blica, não pode deixar de mandar prender até ulterior deliberação o Tenente d'este Corpo Manoel da Silva Cardoso destacado em Nasareth por ter desobedecido a ordem urgente que lhe mandou para recolher-se ao corpo com parte de seu destacamento; desculpando-se pusilanimemente com pedidos da respectiva Camara Municipal. O Tenente Cardoso commetteo uma desobediencia, abandonou-nos no perigo e commetteu um acto de fraqueza indigno de um militar deve ter por norma o dever e a obedi= encia da obrigação de unir-se no perigo a seos companheiros e com elles partilhar dos revezes ou das glorias.

Nesta occasião louvo ao Tenente João José de Freitas e Alferes Amaro Tavares de Macedo pela prom= ptidão com que acodirão a meu chamado apresentando=se n'este quartel. O Commandante Geral Durval Vieira de Aguiar.

Quartel do Commando Geral do Corpo de Policia na Mouraria 21 de Novembro de 1889.

\section{Ordem do Dia n-3}

O Tenente Coronel Commandante Geral faz publico ao corpo que hoje tiverão praça de cornetei= ros da $8^{\mathrm{a}}$ Companhia nas condições regulamentares os individuos de nomes Francisco da Cruz de Jesus e João Martins da Silva. O Commandante Geral Durval Vieira de Aguiar.

Quartel do Commando Geral do Corpo de Policia na Mouraria 22 de Novembro de 1889.

Ordem do Dia n- 4 .

O Tenente Coronel Commandante Geral faz publico para os fins convenientes que tendo destacado para a Cidade de Ilhéus o Capitão Joaquim Baldoino da Silva Commandante da $2^{a}$ Compa $=$ nhia passa a commandal-a o Tenente João José de Freitas, sendo-lhe entregue com as formalidades do estylo. Outro sim, forão vendidos em hasta publica na porta do Thesouro Provincial no dia 14 do corrente por ordem de S. Exª o Snr ${ }^{\sim}$ Conselheiro ex Presidente da Provincia os cavallos denominados

Jatahy, Cangira e Gigante por se acharem imprestaveis para o serviço do policiamento. O Com= mandante Geral Durval Vieira de Aguiar.

Quartel do Commando Geral do Corpo de Policia na Mouraria 23 de Novembro de 1889.

Ordem do Dia n- 5

\section{DESCREVENDO E ANALISANDO AS ABREVIATURAS DE PATENTES}

As abreviaturas constantes no corpus estão representadas tomando a seguinte sistematização: 1) Ordem alfabética da palavra, não do termo abreviativo; 2) Dentro dessa ordem alfabética, tendo em vista que há muitas variantes, obedecemos a quantidade de 
ocorrências dessas abreviaturas no documento; 3) Em seguida, permanecendo a equidade de ocorrências, o critério foi o item mais abreviativo, ou seja, que tinha menos caracteres;4) Se a igualdade se mantivesse, observamos a grafia, se era maiúscula ou minúscula. A partir dos critérios apresentados, chegamos ao seguinte resultado:

Tabela 1. Abreviaturas de patentes por ordem alfabética e sua frequência

\begin{tabular}{|c|c|c|c|}
\hline Abreviaturas & $\begin{array}{c}\text { Frequência } \\
\text { token }\end{array}$ & $\begin{array}{c}\text { Termos de } \\
\text { patente }\end{array}$ & $\begin{array}{c}\text { Frequência } \\
\text { type }\end{array}$ \\
\hline Alfes. & 3 & Alferes & 3 \\
\hline Cap $^{m}$. & 12 & \multirow{3}{*}{ Capitão } & \multirow{3}{*}{14} \\
\hline $\mathrm{Cap}^{\underline{m}}$ & 1 & & \\
\hline $\mathrm{Cap}^{\underline{\underline{n}}}$ & 1 & & \\
\hline Cor $\underline{\underline{\mathrm{el}}}$ & 4 & \multirow{4}{*}{ Coronel } & \multirow{4}{*}{8} \\
\hline $\operatorname{Cor}^{\mathrm{el}}$ & 2 & & \\
\hline $\mathrm{C} \underline{\underline{\underline{\mathrm{el}}}}$ & 1 & & \\
\hline Cor $\stackrel{\text { nel }}{=}$ & 1 & & \\
\hline Sarg $^{\text {to }}$ & 1 & Sargento & 1 \\
\hline Sold $^{\circ}$ & 4 & Soldado & 4 \\
\hline $\operatorname{Ten}^{\mathrm{e}}$ & 8 & \multirow{4}{*}{ Tenente } & \multirow{4}{*}{12} \\
\hline $\mathrm{T}^{\mathrm{e}}$ & 2 & & \\
\hline Ten $^{\mathrm{e}}$ & 1 & & \\
\hline Ten $^{\text {te }}$ & 1 & & \\
\hline $\operatorname{Ten}^{\mathrm{e}} \operatorname{Cor}^{\mathrm{el}}$ & 5 & \multirow{10}{*}{$\begin{array}{l}\text { Tenente } \\
\text { Coronel }\end{array}$} & \multirow{10}{*}{22} \\
\hline $\operatorname{Ten}^{\mathrm{e}} \operatorname{Cor}^{\mathrm{el}}$ & 4 & & \\
\hline Ten $^{\mathrm{e}}$ Coronel & 4 & & \\
\hline $\operatorname{Ten}^{\mathrm{e}} \operatorname{Cor}^{\mathrm{e}} \underline{\mathrm{el}}$ & 2 & & \\
\hline Tene $\operatorname{Cor}^{\mathrm{el}}$ & 2 & & \\
\hline $\mathrm{T}^{\mathrm{e}} \operatorname{Cor}^{\mathrm{el}}$ & 1 & & \\
\hline T.C $\underline{\underline{\underline{\mathrm{el}}}}$ & 1 & & \\
\hline $\operatorname{Tn}^{\mathrm{e}} \operatorname{Cor}^{\mathrm{el}}$ & 1 & & \\
\hline $\operatorname{Ten}^{\underline{e}} \operatorname{Cor}^{\mathrm{el}}$ & 1 & & \\
\hline Tenente Cor ${ }^{\mathrm{el}}$ & 1 & & \\
\hline
\end{tabular}

Fonte: Autoria própria a partir do processamento com AntConc

Como se verifica na tabela 1 , abreviaturas de 7 postos de graduação foram computados nos quarenta fólios editados. Em ordem decrescente de hierarquia militar, temos: Coronel, Tenente Coronel, Capitão, Tenente, Alferes, Sargento e Soldado. Em ordem decrescente em sua frequência type, vemos que Tenente Coronelé a patente que mais aparece (22 vezes) e também é a que possui mais registros de variantes (10). Em seguida, temos a patente de capitão, que ocorre 14 vezes com um registro total de 3 variantes. O que nos chama atenção é que uma das variantes $\left(\mathrm{Cap}^{\mathrm{m}}\right.$.) possui a maior frequência token de todo o grupo de abreviaturas (12 vezes). Tenente vem em seguida com 12 ocorrências type e manifestação de 4 variantes de abreviaturas. Na sequência, temos Coronel (8/4), Soldado 
(4/1), Alferes (3/1) e Sargento (1/1). Podemos concluir que as variantes mais produtivas foram as que representavam as patentes de Oficiais de um escalão superior.

O índice representativo de variação das abreviaturas reafirma o que Flexor (2008) já havia apontado: não há um padrão na formulação das mesmas. Como as ordens do dia não eram escritas a próprio punho pelo comandante, o alto índice de abreviaturas no DET pode ser justificado por tratar-se de uma escrita taquigráfica, ou seja, o Comandante ditava as deliberações do dia e o escrivão da corporação as transcrevia. Esse processo, obviamente, exigia do escriba a habilidade para não se perder no relato, nem desperdiçar o material, que era muito caro à época. Portanto, abreviar era um sinônimo de economia de espaço no papel, por conseguinte, economia de material, além de ser uma forma de acompanhar o tempo de fala da pessoa que está ditando o que deve ser escrito.

Conforme nos aponta Santos (2019), a maior parte das abreviaturas encontradas na documentação editada está ligada diretamente ao campo nocional de termos do militarismo (MARENGO, 2016, MARENGO; CAMBRAIA, 2016), tais como os postos de graduação (Tenente, Tenente Coronel, soldado, alferes, capitão), as formações da corporação (batalhão, destacamento e companhias) ou a ações cotidianas do aquartelamento (juramento, comandada, interinamente).

Retomando o nosso arsenal teórico em relação aos tipos de abreviaturas vimos que os dados não apresentam abreviaturas por apócope ou síncope. Todas as abreviaturas de patente militar são categoricamente por letras sobrescritas. Tal fato, obviamente, não é dissonante de outros estudos realizados com outras tipologias documentais no mesmo século. No entanto, tal indicativo quantitativo das variações de formas abreviadas nos levam a caminhos que devem ser explorados em futuros estudos. $O$ primeiro diz respeito a considerações estritamente linguístico-terminológicas. Dentro da Socioterminologia (FAULSTICH, 2002, p.81-82), as variantes terminológicas linguísticas gráficas são definidas como aquela que se apresentam sob forma gráfica diversificada com base em acordos formais de convenções da língua. O nosso corpus de uma sincronia passada nos revela um processo altamente produtivo de escrita, que é uso de abreviaturas, além de nos apresentar um farto conjunto de dados representativos da não normalização ou normatização de usos abreviativos desses termos. Assim, pensando em um movimento diacrônico é necessário que pensemos em particularidades que promovam uma renovação na definição dada às variantes terminológicas gráficas. Em segundo lugar, é importante que comecemos a passar do nível descritivo para o interpretativo. Como afirmamos, a maioria absoluta de estudos sobre manuscritos dos séculos XVIII e XIX nos apresentam quase sempre o mesmo resultado de descrição: a forma mais produtiva de abreviaturas é por letras sobrescritas. Mas, para além de uma justificativa espacial, certamente deve haver uma justificativa linguística para tal fenômeno.

\section{CONSIDERAÇÕES FINAIS}


Enveredar pelos caminhos da edição de textos é uma das muitas formas de conhecer a história pretérita de um dado povo. Adotamos, portanto, a premissa de Lose (2017) de que os documentos antigos podem ser históricos, ao trazer relatos de momentos importantes que se tornaram emblemáticos na história de uma nação. Dessa forma, o DET é uma fonte histórica que nos permite reviver a atuação pungente da corporação policial na consolidação do nosso país enquanto nação, bem como para o protagonismo da província da Bahia no percurso histórico do Brasil.

Neste artigo tentamos contribuir para o olhar de que as abreviaturas compõem um foco importante da linguagem, em que, segundo Marengo (2018), no campo terminológico é que a atenção às abreviaturas deve ser feita de modo mais incisivo. Assim, aqui procuramos descrever os tipos de abreviaturas presentes no DET 68 e, a partir desse olhar empírico-descritivo, verificar qual a tipologia de abreviaturas mais nos abre espaço para o fenômeno da variação. Vimos que as abreviaturas por letras sobrescritas são de uso categórico no que concerne à terminologia militar de patentes. Como já apontamos em outros momentos, nos propusemos nesse espaço mais a uma descrição do que efetivamente uma análise. No entanto, não desprezamos o espaço aberto para algumas reflexões que serão de suma importância para o desenvolvimento de uma teoria mais consubstanciada de uma (sócio)Terminologia histórica ou diacrônica (MARENGO; SOUZA; FONSECA, 2019).

\section{REFERÊNCIAS}

ACIOLI, V. L. C. A Escrita no Brasil Colônia: um guia para leitura de documentos manuscritos. 2. ed. Recife: UFPE/Fundação Joaquim Nabuco/Editora Massangana, 2003.

ARAÚJO, O. M. Notícias sobre a Polícia Militar da Babia no século XIX. Edição Comemorativa ao $172^{\circ}$ aniversário da Polícia Militar da Bahia. Salvador, 1997.

BERWANGER, A. R.; LEAL, J. E. F. Noções de paleografia e diplomática. $3^{\text {a }}$ ed. Santa Maria, RS: Ed. UFSM, 2008.

CAMBRAIA, C. N. Subsídios para uma proposta de normas de edição de textos antigos para estudos linguísticos In: I Seminário de Filologia e Lingua Portuguesa. São Paulo: FFLCHUSP/ Humanitas, 1999. p.13-23.

Introdução à crítica textual. São Paulo: Martins Fontes, 2005.

CARNEIRO, Z. O. N.; SOUZA, M. I. J. As abreviaturas em Documentos do século XVIII da capitania da Bahia: algumas considerações. Cadernos do CiFEFil, Rio de Janeiro, 2015.

CASTRO, C. et al. Nova História Militar Brasileira. Rio de Janeiro: Editora FGV, 2004.

CUNHA, C.; CINTRA, L. Nova gramática do português contemporâneo. 4. ed. revista e ampliada. Rio de Janeiro: Lexikon Editora Digital, 2007. 
DIAS, M. M.; BIVAR, V. S. B. Paleografia para o período colonial. In: Paleografia e fontes do período colonial brasileiro. Estudos CEDHAL - Nova Série $\mathrm{n}^{\circ}$ 11. São Paulo: Humanitas/FFLCH/USP, 2005.

DOLHNIKOFF, M. História do Brasil Império. São Paulo: Contexto, 2017.

FAULSTICH, E. Variação em terminologia. Aspectos de socioterminologia. In: RAMOS, G. G.; PÉREZ LAGOS, M. F. (coord.). Panorama Actual de la Terminología. Granada: Editorial Comares, p.65-91, 2002.

FLEXOR, M. H. O. Abreviaturas: Manuscritos dos séculos XVI ao XIX. 3 ed. Rio de Janeiro: Arquivo Nacional, 2008.

LIMA, Y. D. Paleografia In: Apostila do curso sobre paleografia. São Paulo: IEB, Universidade de São Paulo, 2006.

LOSE, A. D. Edições de Documentos Históricos: A quem interessam? A quem se destinam? Revista Abralin, v.16, n.2, p. 71-86, Jan./Fev./Mar./Abr. 2017.

MARENGO, S. M. D. A. Variações terminológicas e diacronia: Estudo léxico-social de documentos manuscritos militares dos séculos XVIII e XIX. 2016. 539 pp. Tese (Doutorado em Estudos Linguísticos) - Universidade Federal de Minas Gerais, Belo Horizonte, 2016.

Apontamentos críticos das normas no ofício de editar juramentos d'alma setecentistas In: DUHÁ, A.; SOUZA, A. S. Paleografia e suas interfaces. Salvador: EdUFBA/ Memória \& Arte, 2018. p.276-285.

MAREngO, S. M. D. A.; FreitAG, R. M. K. Para Uma História Do Português Brasileiro em Sergipe: Organizando as Fontes Manuscritas e suas Edições. Revista do Instituto Histórico e Geográfico de Sergipe, Aracaju, v.1, n.46, p.116-129, 2016.

MARENGO, S. M. D. A.; CAMBRAIA, C. N. Estudo socioterminológico da variação/mudança em manuscritos militares dos séculos XVIII E XIX. InterdisciplinarRevista de Estudos em Língua e Literatura, Ano XI, v.24, jan./abr. 2016. p. 203 - 224. Disponível

em: <https://seer.ufs.br/index.php/interdisciplinar/article/download/5415/4440> Acesso em: 18 dez. 2019.

MARENGO, S. M. D. A.; SOUZA, N. L. S.; FONSECA, M. A. C. S. Linguística Forense em diacronia: apontamentos terminométricos da variação defloramento/estupro no Sergipe oitocentista. In: LOPES, N. S.; CARVALHO, C. S.; SANTOS, E. S. (orgs.) Linguagem e sociedade. São Paulo: Blucher, 2019.

MiLlARES CARLO, A. Paleografía Española. Ensayo de una História de la Escritura en España desde el siglo VIII al XVII. Barcelona; Buenos Aires: Labor, 1929.

SANTOS, L. D. S. Da Lei Áurea à Proclamação da República: Edição diplomática e estudo das abreviaturas de um Livro de Registro do Detalhe da Polícia Militar do Estado da Bahia. 2019. 145p. Dissertação (Mestrado em Estudos Linguísticos) - Universidade Estadual de Feira de Santana, Feira de Santana, Bahia, 2019. 


\section{Revista ${ }_{A}$ Cor das Letras}

SPINA, S. Introducão à edótica: Crítica textual. São Paulo: Ars Poetica/ Editora da Universidade de São Paulo, [1977] 1994.

Recebido em: 28/09/2019

Aprovado em: 07/11/2019

Publicado em: 30/04/2020 